\title{
DESEMPENHO AGRONÔMICO DE LINHAS ENDOGÂMICAS ECOMBINADAS DE Capsicum annuum L. EM SISTEMA ORGÂNICO SOB CULTIVO PROTEGIDO ${ }^{1}$
}

\author{
Agronomic performance of recombinant inbred of Capsicum annuum L. lines cultivated \\ under organic system and greenhouse conditions ${ }^{1}$
}

\author{
Sarah Ola Moreira ${ }^{2}$, Rosana Rodrigues ${ }^{3}$, Maria Luíza de Araújo ${ }^{4}$, \\ Elaine Manelli Riva-Souza ${ }^{5}$, Rebeca Lourenço de Oliveira $^{3}$
}

\begin{abstract}
RESUMO
O manejo de plantas em cultivo protegido e a busca de produtos orgânicos pelos consumidores têm sido um desafio para produtores e pesquisadores de hortaliças. Para que essas formas de cultivo proporcionem lucratividade ao produtor e frutos de qualidade para o consumidor, faz-se necessária a busca por genótipos adaptados a esse manejo diferenciado. Neste trabalho, objetivouse avaliar o desempenho de 12 linhas endogâmicas recombinadas de Capsicum annuum L., obtidas do cruzamento entre os acessos UENF 1421 e UENF 1381, em cultivo protegido sob manejo orgânico. O experimento foi instalado em casa de vegetação, na Estação Experimental de Seropédica da PESAGRO-RIO, em blocos casualizados, com quatro repetições. Avaliaram-se o número total de frutos (NTF), peso total de frutos (PTF), peso médio dos frutos (PMF), comprimento dos frutos (CF), diâmetro dos frutos (DF), relação comprimento/diâmetro do fruto (CF/DF) e presença de capsaicina (CAPS). Foram estimados os parâmetros genéticos variâncias genotípica, fenotípica e ambiental, coeficientes de determinação genotípico e de variação genética e o índice de variação. Houve diferença altamente significativa para todas as características, exceto para PTF. As linhas produziram elevado número de frutos, leves e de formatos variados. Somente duas linhas não tiveram pungência e quatro segregaram para CAPS. Todas as características tiveram alta variância genotípica e altos coeficientes de determinação genotípicos, mostrando que os resultados são, predominantemente, de origem genética. Os dados permitiram a indicação preliminar das linhas 5 e 8 para o cultivo orgânico em ambiente protegido.
\end{abstract}

Termos para indexação: Melhoramento de hortaliças, pimentão, pimenta, parâmetros genéticos, capsaicina.

\begin{abstract}
Plant management under greenhouse conditions, associated with search for ecological products by consumers, has been a challenge for both farmers and vegetable researchers. Obtaining profit and quality depends on adapted genotypes that can be grown using an adequate management. The aim of this work was to study the agronomic performance of 12 recombinant inbred chili pepper (Capsicum annuum L.) lines, from crosses between UENF 1421 and UENF 1381 accessions, under greenhouse conditions and using an organic system. The experiment was carried out at Seropédica Experimental Station of PESAGRO-RIO, in randomized block design, with four replications. The following variables were evaluated: total number of fruits (TNF); total fruit weight (TFW); average weight of fruits (MWF); fruit length (FL); fruit diameter (FD); length and diameter fruit ratio (LDFR), and capsaicin presence (CAPS). Genotypic, phenotypic and environmental variances, as well as genotypic determination coefficient and variation index were estimated. There was highly significant difference for all traits unless TFW. The lines produced a high number of fruits, with low weight and with variability in shape among lines. Absence of capsaicin was observed only in two lines and other three lines segregated for capsaicin presence. High values of genotypic variance and genotypic determination coefficient were estimated for all traits, indicating that the results were due to genetic causes. The data pointed to a preliminary indication of lines 5 and 8 for cultivation in an organic system under greenhouse conditions.
\end{abstract}

Index terms: Plant breeding, pepper, chili pepper, genetic parameters, capsaicin.

(Recebido em 3 de outubro de 2008 e aprovado em 26 de novembro de 2009)

\section{INTRODUÇÃO}

A crescente demanda por hortaliças de alta qualidade e ofertadas durante todo o ano têm contribuído para o investimento em novos sistemas de cultivo que permitam produção adaptada a diferentes regiões e condições adversas de ambiente. No Brasil, o cultivo de hortaliças em ambiente protegido vem ganhando espaço entre os produtores, em razão, principalmente, da relativa

\footnotetext{
${ }^{1}$ Parte da dissertação de mestrado apresentado à Universidade Estadual do Norte Fluminense Darcy Ribeiro (UENF)

2Universidade Estadual do Norte Fluminense Darcy Ribeiro/UENF - Centro de Ciências e Tecnologias Agropecuárias/CCTA - Laboratório de Melhoramento Genético Vegetal/LMGV - Avenida Alberto Lamego - 2000 - 28013-602 - Campos dos Goytacazes, RJ - sarah.ola@gmail.com ${ }^{3}$ Universidade Estadual do Norte Fluminense Darcy Ribeiro/UENF - Centro de Ciências e Tecnologias Agropecuárias/CCTA - Laboratório de Melhoramento Genético Vegetal/LMGV - Campos dos Goytacazes, RJ

${ }^{4}$ Empresa de Pesquisa Agropecuária do Estado do Rio de Janeiro/PESAGRO - Estação Experimental de Seropédica/EES - Seropédica, RJ ${ }^{5}$ Instituto Capixaba de Pesquisa, Assistência Técnica e Extensão Rural/INCAPER - Venda Nova do Imigrante, ES
} 
facilidade de manejo quando comparadas às do sistema convencional em campo aberto (Scivittaro et al., 1999; Carrijo et al., 2004).

Capsicum annuum L. é uma das espécies mais indicadas para o cultivo protegido, pois este sistema propicia grande produtividade, melhor qualidade dos frutos, cultivo durante o ano todo e em locais onde as condições climáticas são limitantes (Scivittaro et al., 1999; Lúcio et al., 2004, 2006; Fontes et al., 2005b).

Dentre as vantagens do cultivo protegido, citamse o controle total ou parcial da velocidade do vento, da umidade relativa, da evaporação, da temperatura ambiente, da amplitude térmica do solo e a proteção contra chuvas pesadas (Eklund et al., 2005; Fontes et al., 2005a,b). Além disso, o cultivo protegido melhora a qualidade do fruto, diminui o consumo de água e fertilizantes, permite a antecipação da colheita, a produção fora da época, o melhor preço, a maior produtividade e a preservação do meio ambiente (Scivittaro et al., 1999; Figueiredo et al., 2004).

Outra forma de cultivo que está crescendo nos últimos anos é o sistema orgânico, principalmente, porque, na última década, o nível de conscientização quanto às relações da agricultura com o ambiente, aos recursos naturais e à qualidade dos alimentos, cresceu substancialmente (Oliveira et al., 2005). Com isso, a demanda por alimentos saudáveis, livres de resíduos tóxicos, e a necessidade de preservação ambiental têm crescido em todo o mundo (Vidal et al., 2007).

Os preços dos produtos orgânicos são diferenciados, servindo de incentivo para os produtores. Segundo Martins et al. (2006), o preço médio do quilo de pimentão sob cultivo convencional no estado de São Paulo, em 2004, foi R \$2,52, já o praticado para o produto orgânico foi $\mathrm{R} \$ 7,77$, representando um aumento de $208 \%$. Porém, a competitividade desses produtos depende, em parte, da geração de conhecimentos e de bases tecnológicas apropriadas que assegurem a sua sustentabilidade, como a melhoria nas técnicas de manejo, nos insumos utilizados e nas cultivares, que devem ser adaptadas a essa forma de cultivo (Ventura et al., 2007).

Apesar da complexidade do sistema de produção, pesquisadores estão tentando entender os fatores que afetam a produtividade das plantas, visando a obter o máximo de produtividade das culturas (Caliman et al., 2005). Em razão da necessidade de manejo diferenciado, a produção de hortaliças sob condições protegidas e cultivo orgânico demanda cultivares adaptadas, que proporcionem o máximo de rendimento e frutos de alta qualidade.

Trabalhos de melhoramento envolvendo a obtenção de linhas recombinadas não são comuns em pimentas, e nem mesmo em pimentão, espécie para a qual, muitas pesquisas se detêm na obtenção de híbridos, para a exploração da heterose e de genes dominantes para resistência às doenças. Entretanto, o alto custo das sementes híbridas pode inviabilizar o cultivo desses genótipos por pequenos produtores. A utilização de variedades de polinização aberta, que possuam resistência às principais doenças, pode suprir as necessidades desse nicho de mercado.

Conduziu-se este trabalho, com o objetivo de avaliar 12 linhas endogâmicas recombinadas de pimenta, com resistência à mancha-bacteriana, cultivadas em sistema orgânico sob cultivo protegido no município de Seropédica - RJ.

\section{MATERIAL E MÉTODOS}

O experimento foi conduzido em cultivo protegido, na Estação Experimental de Seropédica - RJ, da Empresa de Pesquisa Agropecuária do Estado do Rio de Janeiro (PESAGRO - RIO), localizada a uma latitude 22 $44^{\prime} 38^{\prime \prime}$ Sul e a uma longitude $43^{\circ} 42^{\prime} 27^{\prime \prime}$ Oeste, e altitude de 26 metros.

Foram avaliadas 12 linhas endogâmicas recombinadas correspondentes à geração $\mathrm{F}_{7}$ do cruzamento entre o acesso UENF 1421, um pimentão suscetível à mancha-bacteriana, e o acesso UENF 1381, uma pimenta resistente à mancha-bacteriana que vem sendo utilizada como fonte de resistência a essa doença no programa de melhoramento desenvolvido pela UENF (Riva et al., 2004). As linhas recombinadas foram obtidas pelo método do SSD (Single Seed Descent) por Riva (2006) e são resistentes à mancha-bacteriana.

O delineamento experimental foi em bloco ao acaso, com quatro repetições. Cada repetição foi constituída de seis plantas úteis, dispostas em duas linhas. A adubação foi realizada com base em resultados preliminares obtidos em experimentos conduzidos na área e complementados com o Manual de Adubação para o Estado do Rio de Janeiro (Polli et al., 1998).

Foram realizadas oito colheitas no período de 10 de julho a 8 de novembro de 2007. As características avaliadas foram: número total de frutos (NTF); peso total de frutos (PTF), em gramas; peso médio dos frutos (PMF), em g/ fruto, obtido pela divisão do PTF pelo NTF; comprimento dos frutos (CF), em mm; diâmetro dos frutos (DF), em mm, ambos medidos em uma amostra aleatória de cinco frutos por linha, sendo considerada a maior medida; relação comprimento/diâmetro do fruto $(\mathrm{CF} / \mathrm{DF})$, obtida pela divisão do CF pelo DF; presença ou ausência de capsaicina (CAPS), determinada numa porção da placenta dos frutos (aproximadamente, $1 \mathrm{~cm}$ ), que foi imersa em uma solução 
de $3 \mathrm{~mL}$ de vanadato de amônio, durante o período de 5 horas, segundo adaptações de Riva (2006) no método de Derera (2000). Para determinação da CAPS, foi avaliado um fruto por planta. As plantas também foram observadas quanto à reação à mancha-bacteriana em condições de ocorrência natural da doença. A análise de variância foi realizada seguindo a descrição feita por Cruz et al. (2004) e as médias foram agrupadas pelo teste proposto por Scott Knott.

Foram estimados os seguintes parâmetros genéticos: variância genotípica média $\left(\hat{\sigma}_{g}^{2}\right)$; variância fenotípica média $\left(\hat{\sigma}_{f}^{2}\right)$; variância ambiental média $\left(\hat{\sigma}^{2}\right)$; coeficiente de determinação genotípico $\left(H^{2}\right)$; coeficiente de variação genético $\left(C V_{g}\right)$ e índice de variação $\left(C V_{g} /\right.$ $C V_{e}$ ), segundo Cruz (2001). Para a análise dos dados, foi utilizado o Programa Computacional Genes (Cruz, 2001).

\section{RESULTADOS E DISCUSSÃO}

O resultado da análise de variância demonstrou valores de $\mathrm{F}$ significativos $(\mathrm{p}<0,01)$ para todas as características, exceto PTF. As linhas avaliadas apresentaram alto NTF (284, em média), produção total de frutos em torno de $2210 \mathrm{~g}$, com PMF de $8,4 \mathrm{~g}$. A relação $\mathrm{CF} /$ DF foi de 3,89, o que representa frutos classificados como alongados ou piramidal (Peixoto et al., 1999; Scivittaro et al., 1999; Moreira et al., 2006).
Os coeficientes de variação (CV) para as características de produção foram de 20,5 \% para NTF, 23,0 \% para PTF e 19,7 \% para PMF. Já, para a relação CF/ $\mathrm{DF}$, o CV foi de 17,04 \%. Esses valores foram considerados elevados a médios (Gomes \& Garcia, 2002). Deve-se considerar que as injúrias, às quais naturalmente as plantas são submetidas, durante os tratos culturais e colheita dos frutos, assim como outras variações ambientais que fazem com que a produção individual das plantas seja afetada ao longo das colheitas, podem aumentar o CV (Lucio et al., 2006). Todavia, os valores de CV obtidos neste trabalho são bem inferiores aos normalmente encontrados na literatura. Sousa \& Maluf (2003) registraram um CV de 45,54 \% para a produção total de frutos de pimenta. Por sua vez, os $\mathrm{CV}$ s registrados para CF e DF $(8,05 \%$ e $12,06 \%$, respectivamente) foram considerados baixos.

O PMF variou entre 5,86 g/fruto (linha 2) e 14,07 $\mathrm{g} /$ fruto (linha 1) (Tabela 1). Esses frutos, embora possam ser considerados pequenos quando comparados com os de cultivares de pimenta-jalapeño ou de pimenta-doce (ambas da espécie C. annuum), que possuem frutos com peso entre 45 e $60 \mathrm{~g}$, assemelham-se ao peso médio da pimenta-de-cheiro, da espécie $C$. chinense Jacq. (Moreira et al., 2006).

Tabela 1 - Número total de frutos (NTF); peso total de frutos (PTF), em gramas; peso médio dos frutos (PMF), em g/ fruto; comprimento dos frutos $(\mathrm{CF})$, em mm; diâmetro dos frutos (DF), em mm; relação comprimento/diâmetro do fruto (CF/DF) e presença ou ausência de capsaicina (CAPS) de 12 linhas recombinadas de C. annuum, cultivadas sob cultivo protegido em manejo orgânico. PESAGRO/EES, 2007.

\begin{tabular}{cccccccc}
\hline LINHAS RECOMBINADAS & NTF $^{1}$ & PTF & PMF & CF & DF & CF/DF & CAPS $^{2}$ \\
\hline 1 & $156,00 \mathrm{~B}$ & $2001,25 \mathrm{~A}$ & $14,07 \mathrm{~A}$ & $83,07 \mathrm{~A}$ & $21,67 \mathrm{~A}$ & $3,93 \mathrm{~B}$ & $\mathrm{~A}$ \\
2 & $357,25 \mathrm{~A}$ & $2040,00 \mathrm{~A}$ & $5,86 \mathrm{~B}$ & $59,45 \mathrm{C}$ & $16,85 \mathrm{~B}$ & $3,83 \mathrm{~B}$ & $\mathrm{~S}$ \\
3 & $344,75 \mathrm{~A}$ & $2235,00 \mathrm{~A}$ & $6,47 \mathrm{~B}$ & $74,20 \mathrm{~B}$ & $19,40 \mathrm{~A}$ & $3,96 \mathrm{~B}$ & $\mathrm{P}$ \\
4 & $289,75 \mathrm{~A}$ & $2445,00 \mathrm{~A}$ & $8,57 \mathrm{~B}$ & $85,55 \mathrm{~A}$ & $19,95 \mathrm{~A}$ & $4,39 \mathrm{~B}$ & $\mathrm{P}$ \\
5 & $338,50 \mathrm{~A}$ & $2162,50 \mathrm{~A}$ & $6,40 \mathrm{~B}$ & $43,70 \mathrm{D}$ & $23,55 \mathrm{~A}$ & $1,87 \mathrm{C}$ & $\mathrm{A}$ \\
7 & $263,50 \mathrm{~B}$ & $1692,50 \mathrm{~A}$ & $6,78 \mathrm{~B}$ & $60,35 \mathrm{C}$ & $15,20 \mathrm{~B}$ & $4,09 \mathrm{~B}$ & $\mathrm{P}$ \\
8 & $176,25 \mathrm{~B}$ & $1618,75 \mathrm{~A}$ & $9,25 \mathrm{~A}$ & $68,85 \mathrm{~B}$ & $19,10 \mathrm{~A}$ & $3,67 \mathrm{~B}$ & $\mathrm{~S}$ \\
9 & $345,75 \mathrm{~A}$ & $2546,25 \mathrm{~A}$ & $7,42 \mathrm{~B}$ & $59,40 \mathrm{C}$ & $20,20 \mathrm{~A}$ & $3,13 \mathrm{C}$ & $\mathrm{P}$ \\
10 & $315,50 \mathrm{~A}$ & $2264,25 \mathrm{~A}$ & $7,24 \mathrm{~B}$ & $56,35 \mathrm{C}$ & $22,00 \mathrm{~A}$ & $2,59 \mathrm{C}$ & $\mathrm{P}$ \\
11 & $230,00 \mathrm{~B}$ & $2322,50 \mathrm{~A}$ & $10,60 \mathrm{~A}$ & $71,50 \mathrm{~B}$ & $18,85 \mathrm{~A}$ & $3,98 \mathrm{~B}$ & $\mathrm{P}$ \\
\hline $\mathrm{CV}(\%)$ & $245,75 \mathrm{~B}$ & $2916,25 \mathrm{~A}$ & $11,78 \mathrm{~A}$ & $81,30 \mathrm{~A}$ & $20,60 \mathrm{~A}$ & $4,10 \mathrm{~B}$ & $\mathrm{~S}$ \\
\hline
\end{tabular}

${ }^{1}$ Médias seguidas pela mesma letra, na coluna, não diferem significativamente entre si, pelo teste de agrupamento de médias de Scott-Knott;

${ }^{2} \mathrm{P}$ = presença de capsaicina; $\mathrm{A}$ = ausência de capsaicina; $\mathrm{S}$ = segregação para presença de capsaicina. 
O peso médio dos frutos foi obtido pela divisão dos valores de PTF pelo NTF. Os maiores valores de NTF foram registrados para as linhas 2, 3, 5, 8, 9 e 12, que, simultaneamente, tiveram os menores valores de PMF. Esses valores fundamentam a falta de diferenças significativas para PTF. A maior produção foi obtida pela linha 11 , com 2916,25 g/parcela, o que representa uma produção de 486,04 g/planta. Num espaçamento de $1,0 \mathrm{x}$ $0,5 \mathrm{~m}$, a produtividade seria de $9720 \mathrm{~kg} /$ hectare, comparável à produtividade de cultivares comerciais de pimenta (Vilela \& Junqueira, 2006). Em híbridos de pimenta (Capsicum chinense), Sousa \& Maluf (2003) obtiveram uma produção média por planta que variou entre $76,8 \mathrm{~g}$ e $591,1 \mathrm{~g}$, para os genitores utilizados em esquema de dialelo, e entre 75,8 e 705,5 g, para os híbridos obtidos destes cruzamentos. A produção por planta obtida neste estudo foi maior que a produção por planta registrada para nove dos dez híbridos produzidos no estudo de Sousa \& Maluf (2003).

$\mathrm{O}$ agrupamento das médias da relação $\mathrm{CF} / \mathrm{DF}$ dividiu as linhas de acordo com o formato do fruto. As linhas 5, 8 e 9 (agrupados com a letra C) tiveram CF/DF entre 1,87 e 3,13 e são classificados como frutos de forma retangular ou cônica. As linhas agrupadas com a letra B são frutos de formato alongado ou piramidal (Peixoto et al., 1999; Scivittaro et al., 1999; Moreira et al., 2006). A linha 12 (letra A) obteve $\mathrm{CF} / \mathrm{DF}$ de 7,15 , considerados frutos de formato cilíndrico, similares aos da cultivar 'De Cayenne', desenvolvida pela Isla (ISLA Sementes, 2007).

Houve segregação para a presença da capsaicina em quatro linhas estudadas (linhas 2, 7, 11 e 12). Moreira et al. (2006) registraram que a produção de capsaicinóides na placenta dos frutos de pimenta varia tanto em função dos genótipos quanto das condições ambientais em que as plantas são cultivadas, sendo, portanto, uma característica difícil de ser manipulada em função da sua grande instabilidade. Apenas as linhas 1 e 5 não apresentaram pungência, sendo essas linhas indicadas para o consumo como pimentas doces.

Os parâmetros genéticos estudados revelaram que, exceto para PTF, a variância genotípica foi alta para todas as características estudadas e o coeficiente de determinação genotípico foi superior a 82 \% (Tabela 2). A baixa variância ambiental indicou um bom controle da área experimental, já que a contribuição do ambiente, que mascara os efeitos genéticos, foi reduzida. O PTF apresentou alta variância ambiental e baixo coeficiente de determinação genotípico. Esses dados enfatizam a importância da seleção de genótipos específicos para determinados ambientes e formas de cultivo e também mostra a necessidade de testar esses genótipos em vários ambientes e anos, buscando entender os fatores ambientais que maximizam a produção de frutos. A característica de maior variância genotípica e, consequentemente, o maior coeficiente de determinação genotípico, é o comprimento do fruto, demonstrando a baixa influência do ambiente sobre essa variável. Os índices de variação das características NTF, PMF, CF, DF e CF/DF foram superiores à unidade, indicando uma situação favorável à seleção (Cruz et al., 2004).

Em relação à ocorrência de doenças, embora tenha sido observada a presença de plantas de tomateiro com sintomas de mancha-bacteriana em áreas contíguas à área onde as pimentas estavam sendo testadas, não houve sintomas da doença nas plantas de pimenta durante a condução do experimento.

Tabela 2 - Estimativa da variância genotípica média $\left(\hat{\sigma}_{g}^{2}\right)$; variância fenotípica média $\left(\hat{\sigma}_{f}^{2}\right)$; variância ambiental média $\left(\hat{\sigma}^{2}\right)$; coeficiente de determinação genotípico $\left(H^{2}\right)$; coeficiente de variação genético $\left(C V_{g}\right)$ e do índice de variação $\left(C V_{g} / C V_{e}\right)$ em seis características agronômicas de 12 linhas endogâmicas recombinadas de Capsicum annuum sob cultivo protegido em manejo orgânico. PESAGRO/EES, 2007.

\begin{tabular}{cccccccc}
\hline PARÂMETROS GENÉTICOS & NTF $^{1}$ & PTF & PMF & & CF & DF & CF/DF \\
\hline$\hat{\sigma}_{f}^{2}$ & 4889,57 & 125515,50 & 6,49 & 180,47 & 9,48 & 1,58 \\
$\hat{\sigma}^{2}$ & 847,44 & 64781,08 & 0,69 & 7,74 & 1,33 & 0,11 \\
$\hat{\sigma}_{g}^{2}$ & 4042,13 & 60734,42 & 5,81 & 172,73 & 8,15 & 1,47 \\
$H^{2}$ & 82,67 & 48,39 & 89,42 & 95,71 & 85,94 & 93,03 \\
$C V_{g}$ & 22,36 & 11,14 & 28,61 & 19,02 & 14,91 & 31,14 \\
$C V_{g} / C V_{e}$ & 1,09 & 0,48 & 1,45 & 2,36 & 1,24 & 1,83 \\
\hline
\end{tabular}

${ }^{1}$ NTF: número total de frutos; PTF: peso total de frutos; PMF: peso médio dos frutos; CF: comprimento de fruto; DF: diâmetro de fruto e CF/DF: relação comprimento e diâmetro. 


\section{CONCLUSÕES}

No sistema orgânico em cultivo protegido, as linhas endogâmicas recombinadas testadas apresentaram variação para as características estudadas, produção elevada e diferentes formatos de frutos, possibilitando a seleção de genótipos com adaptação ao manejo empregado. Para todas as características testadas, com exceção do PTF, a variância genotípica, o coeficiente de determinação genotípico e o índice de variação foram altos. No sistema orgânico sob cultivo protegido, recomenda-se a linha 5 para ser utilizada como pimentadoce, por produzir frutos com peso médio de $6,4 \mathrm{~g}$ e ter produtividade média de $7208,33 \mathrm{~kg} / \mathrm{ha}$. Entre as pungentes, a linha 8 destacou-se pela produtividade média de 8487,50 $\mathrm{kg} / \mathrm{ha}$ e formato cônico.

\section{AGRADECIMENTOS}

Os autores agradecem à Coordenação de Aperfeiçoamento de Pessoal de Nível Superior (CAPES) pela concessão da bolsa de Mestrado à primeira autora, $\mathrm{e}$ aos funcionários de campo da PESAGRO-RIO/EES, especialmente ao Engenheiro Agrônomo Hélio Vasconcellos, pelo auxílio na condução do experimento.

\section{REFERÊNCIAS BIBLIOGRÁFICAS}

CALIMAN, F.R.B.; SILVA, D.J.H.; FONTES, P.C.R.; STRINGHETA, P.C.; MOREIRA, G.R.; CARDOSO, A.A. Avaliação de genótipos de tomateiro cultivados em ambiente protegido e em campo nas condições edafoclimáticas de Viçosa. Horticultura Brasileira, Brasília, v.23, n.2, p.255-259, 2005.

CARRIJO, A.O.; VIDAL, M.C.; REIS, N.V.B.; SOUZA, R.B.; MAKISHIMA, N. Produtividade do tomateiro em diferentes substratos e modelos de casas de vegetação. Horticultura Brasileira, Brasília, v.22, n.1, p.5-9, 2004.

CRUZ, C.D. Programa genes versão Windows: aplicativo computacional em genética e estatística. Viçosa, MG: UFV, 2001. 648p.

CRUZ, C.D.; REGAZZI, A.J.; CARNEIRO, P.C.S. Modelos biométricos aplicados ao melhoramento de plantas. 3.ed. Viçosa, MG: UFV, 2004. v.1, 480p.

DERERA, F. Condiment paprika: breeding, harvesting \& commercialization. [S.1.: s.n.], 2000. 33p.
EKLUND, C.R.B.; CAETANO, L.C.S.; SHIMOYA, A.; FERREIRA, J.M.; GOMES, J.M.R. Desempenho de genótipos de tomateiro sob cultivo protegido. Horticultura Brasileira, Brasília, v.23, n.4, p.1015-1017, 2005.

FIGUEIREDO, E.B.; MALHEIROS, E.B.; BRAZ, L.T. Interação genótipo $\mathrm{x}$ ambiente em cultivares de alface na região de Jaboticabal. Horticultura Brasileira, Brasília, v.22, n.1, p.66-71, 2004.

FONTES, P.C.R.; DIAS, E.N.; GRAÇA, R.N. Acúmulo de nutrientes e métodos para estimar doses de nitrogênio e potássio na fertirrigação do pimentão. Horticultura Brasileira, Brasília, v.23, n.2, p.275-280, 2005a.

FONTES, P.C.R.; DIAS, E.N.; SILVA, D.J.H. Dinâmica de crescimento, distribuição de matéria seca na planta e produção de pimentão em ambiente protegido.

Horticultura Brasileira, Brasília, v.23, n.1, p.94-99, 2005b.

GOMES, F.P.; GARCIA, C.H. Estatística aplicada a experimentos agronômicos e florestais: exposição com exemplos e orientações para o uso de aplicativos. Piracicaba: FEALQ, 2002. 309p.

ISLA SEMENTES. Pimenta. Disponível em: <http:// iwww.isla.com.br >. Acesso em: $10 \mathrm{dez} .2007$.

LÚCIO, A.D.; LORENTZ, L.H.; BOLIGON, A.A.; LOPES, S.J.; STORCK, L.; CARPE,S R.H. Variação temporal da produção de pimentão influenciada pela posição e características morfológicas das plantas em ambiente protegido. Horticultura Brasileira, Brasília, v.24, n.1, p.31-35, 2006.

LÚCIO, A.D.; MELLO, R.M.; STORCK, L.; CARPES, R.H.; BOLIGON, A.A.; ZANARDO, B. Estimativa de parâmetros para o planejamento de experimentos com a cultura do pimentão em área restrita. Horticultura Brasileira, Brasília, v.22, n.4, p.766-770, 2004.

MARTINS, V.A.; CAMARGO FILHO, W.P.; BUENO, C.R.F. Preços de frutas e hortaliças da agricultura orgânica no mercado varejista da cidade de São Paulo. Informações Econômicas, São Paulo, v.36, n.9, p.42-52, 2006.

MOREIRA, G.R.; CALIMAN, F.R.B.; SILVA, D.J.H.; RIBEIRO, C.S.C. Espécies e variedades de pimenta. Informe Agropecuário, Belo Horizonte, v.27, n.235, p.1629, 2006. 
OLIVEIRA, F.L.; RIBAS, R.G.T.; JUNQUEIRA, R.M.; PADOVAN, M.P.; GUERRA, J.G.M.; ALMEIDA, D.L.; RIBEIRO, R.L.D. Desempenho do consórcio entre repolho e rabanete com pré-cultivo de crotalária, sob manejo orgânico. Horticultura Brasileira, Brasília, v.23, n.2, p.184-188, 2005.

PEIXOTO, J.R.; RAMOS, R.S.; FARIAS JÚNIOR, B.; SILVA, C.M.; ANGELIS, B. de. Avaliação de genótipos de pimentão no período de inverno em Araguari, MG. Pesquisa Agropecuária Brasileira, Brasília, v.34, n.10, p.1865-1869, 1999.

POLLI, H. de. Manual de adubação para o Rio de Janeiro. Seropédica: Universidade Rural, 1998. 179p.

RIVA, E.M. Uso dos métodos genealógico e "single seed descent" (SSD) para obtenção de linha de pimentão resistentes à mancha bacteriana. 2006. 101f. Tese (Doutorado em Produção Vegetal)-Universidade Estadual do Norte Fluminense Darcy Ribeiro, Campos dos Goytacazes, 2006.

RIVA, E.M.; RODRIGUES, R.; PEREIRA, M.G.; SUDRÉ, C.P.; KARASAWA, M.; AMARAL JÚNIOR, A.T. Inheritance of bacterial spot disease in Capsicum anпиит L. Crop Breeding and Applied Biotechnology, Londrina, v.4, n.4, p.490-494, 2004.
SCIVITTARO, W.B.; MELO, A.M.T.; AZEVEDO FILHO, J.A.; CARVALHO, C.R.L.; RAMOS, M.T.B.

Caracterização de híbridos de pimentão em cultivo protegido. Horticultura Brasileira, Brasília, v.17, n.2, p.147-150, 1999.

SOUSA, J.A.; MALUF, W.R. Diallel analyses and estimation of genetic parameters of hot pepper (Capsicum chinense Jacq). Scientia Agrícola, Piracicaba, v.60, p.105-113, 2003.

VENTURA, S.R.S.; CARVALHO, A.G.; ABBOUD, A.C.S.; RIBEIRO, R.L.D. Influência das doses de nitrogênio e das coberturas vivas do solo em cultivo orgânico de berinjela, na incidência de Corythaica cyathicollis em diferentes períodos do dia. Revista Biotemas, Florianópolis, v.20, n.4, p.59-63, 2007.

VIDAL, V.L.; JUNQUEIRA, A.M.R.; PEIXOTO, N.; MORAES, E.A. Desempenho de feijão-vagem arbustivo, sob cultivo orgânico em duas épocas. Horticultura Brasileira, Brasília, v.25, n.1, p.10-14, 2007.

VILELA, N.J.; JUNQUEIRA, K.P. Coeficientes técnicos, custos, rendimentos e rentabilidade das pimentas. Informe Agropecuário, Belo Horizonte, v.27, n.235, p.104-108, 2006. 